\title{
Macroscopic Findings Sponsor Defined Identifier
}

National Cancer Institute

\section{Source}

National Cancer Institute. Macroscopic Findings Sponsor Defined Identifier. NCI

Thesaurus. Code C119872.

One or more sponsor defined characters used to identify, name, or characterize the macroscopic findings assessment. 